\title{
GREEN SYNTHESIS OF SILVER NANOPARTICLES USING CHITOSAN HYDROLYSATE AS STABILIZING AGENT AND THEIR ANTIBACTERIAL ACTIVITY
}

\author{
Endang Susilowati ${ }^{1} *$ Maryani $^{2}$, Ashadi $^{1}$
}

\begin{abstract}
1.Chemistry Department FKIP Universitas Sebelas Maret Surakarta Indonesia, Jl. Ir Sutami 36 A Surakarta Indonesia 53126

2.Medical Faculty Universitas Sebelas Maret Surakarta Indonesia Jl. Ir Sutami 36 A Surakarta Indonesia 53126
\end{abstract}

Submitted: 05-09-2014

Revised: $20-10-2014$

Accepted: $20-12-2014$

*Corresponding author Endang Susilowati

Email:

endwati@yahoo.co.id

\begin{abstract}
Silver nanoparticles were successfully synthesized with chitosan hydrolysate as stabilizing agent at room temperature. Silver nitrate, glucose and sodium hydroxide were used as silver precursor, reducing agent and accelerator respectively. Chitosan hydrolysate was produced by enzymatic process with papain enzyme. Molecular weight of chitosan hydrolysate determined by viscosimetry method based on Mark-Howink equation. The effect of molecular weight of chitosan hydrolysate as stabilizing agent and $\mathrm{AgNO}_{3}$ concentration toward surface plasmon resonance (SPR) of silver nanoparticle was investigated. It is also reported the antibacterial activity of silver-chitosan nanocomposites against Staphylococcus aureus and Escherichia coli. The products of silver nanoparticles were characterized by UV-Vis spectroscopy and transmission electron microscopy (TEM). The result showed that the formation of silver nanoparticles was shown by the appearance of surface plasmon resonance (SPR) at $403-421 \mathrm{~nm}$ from the corresponding UV-Vis spectra. The molecular weight of chitosan hydrolysate affects the absorbance intensity and the wavelength of SPR. Silver nanoparticles were spherical in shape as identified by TEM images with size in range of $4-26 \mathrm{~nm}$. The silver nanoparticles have showed high antibacterial activity against Escherichia coli and Staphylococcus aureus.
\end{abstract}

Key word: green synthesis, silver nanoparticles, chitosan hydrolysate, stabilizing agent, antibacterial activity

\section{INTRODUCTION}

In recent years, silver nanoparticles have attracted considerable attention for medical applications due to their excellent properties such as antibacterial activity. Silver can be used to control bacterial growth in a variety of medical applications. Silver nanoparticle dressing can be used on second degree burn wound and can decrease the risk of wound infection and accelerate wound healing (Chen $e t$ al., 2006). Plastic catheters coat with bioactive silver nanoparticles are non-toxic and capable of targeted and sustained release of silver at the implantation site. Because of their demonstrated antimicrobial properties, they may be useful in reducing the risk of infectious complications in patients with indwelling catheters (Roe et al., 2009).

Silver nanoparticles can be synthesized using various methods, such as chemical reduction (Honary et al., 2011), electrochemical (Vorobyova et al., 1999), $\gamma$-radiation (Shameli et al., 2010), etc. However, the most popular preparation of $\mathrm{Ag}$ colloids is chemical reduction or "wet" chemical reduction of silver ions (Chudasana et al., 2010). In general, the synthesis of silver nanoparticles in solution is carried out by the use of the following components: i) metal precursor; ii) reducing agent and iii) stabilizing agent. The mechanism of formation of colloidal solutions from the reduction of silver(I) ions consists of two stages: nucleation and growth. The nucleation step requires high activation energy while the growing step requires low activation energy. The size and the shape of the nanoparticles will depend on the relative rates of these processes that can be controlled through the adjustment of the reaction parameters (concentration, temperature, $\mathrm{pH}$, reducing ability, etc.) (GarciaBarrasa et al., 2011).

In many researchs, polymers have been used as stabilizers to provide stability for the metal nanoparticles against oxidation, 
agglomeration, and precipitation (Faraha et al., 2008). Preparations of silver nanoparticles in various polymers have been published to give well-dispersed silver nanoparticles, such as polyvinylpyrrolidine (PVP) (Zheng et al., 2001), polyethylene glycol (Luo et al., 2005) and poly (vinyl alcohol) (Zhou et al., 1999). Natural polymers have also been used because they are non-toxic and biocompatible. Cellulose (Cai et al., 2009), chitosan (Huang et al., 2004), and starch (Raveendran el al., 2003) have been used as matrices or stabilizers for preparation of metallic nanoparticles. The present work used chitosan hydrolysate as stabilizing agent. Chitosan hydrolysate is degraded chitosan by hydrolysis. Chitosan is a polysaccharide biopolymer derived from naturally occurring chitin, displays unique polycationic, chelating, due to the presence of active amino and hydroxyl functional groups. Chitosan also has good biocompatibility, biodegradability and antimicrobial activity (Pranoto et al., 2005). Chitosan hydrolysate have higher antibacterial activity than chitosan due to low molecular weight. Therefore, chitosan hydrolysate can act as stabilizing agent as well as increasing antibacterial activity of the colloidal silver nanoparticles.

The chitosan hydrolysate can be prepared by enzymatic and chemical degradation of the chitosan polymer chain. The enzymatic process of chitosan hydrolysate preparation seems to be generally preferable to chemical reactions because the course under gentle condition and product distribution can be controlled more readily, inspite of the faster rate of chemical reaction. The enzymatic method also minimizes alteration in the chemical nature of the product. However, the expensive cost of the specific enzymes such as chitosanase and chitinase inhibits their use in industrial scale (Qin at al., 2002). Recently, several hydrolytic enzymes such as $\alpha$-amilase, cellulase, pectinase and papain were found to catalyze the cleavage of glycosidic linkage in chitosan ( Xie, 2011; Lin et al., 2002). In this study, the cheap commercially available papain was used to prepare chitosan hydrolysate.

Chitosan hydrolysate as a stabilizer agent has a weakness, because chitosan hydrolysate only soluble in aqueous solution of organic and mineral acids (Kim et al., 2006). In this study, the synthesis of silver nanoparticles using glucose as a reductant with $\mathrm{NaOH}$ as an accelerator (Darroudi et al., 2010). Therefore, the new strategy to be done is the formation of silver nanoparticles through gel phase. The colloidals of silver nanoparticles was obtained by dissolving gel to the chitosan hydrolysate solution.

Green synthesis of silver nanoparticles via chemical reduction has been performed using silver nitrate as the metal precursor, glucose as a reduction agent, chitosan hydrolysate as stabilizing agent, water as solvent and sodium hydroxide as accelerator. The synthesis was carried out at room temperature and ambient pressure. The effect of molecular weight of hydrolysate chitosan and silver nitrate concentration toward surface plasmone resonance (SPR) of the resulted silver nanoparticles was investigated. The size and distribution of silver nanoparticle was also investigated. In addition, the effect of silver nanoparticle toward antibacterial activity to Escherichia coli and Staphylococcus aureus was also studied.

\section{MATERIAL AND METHODS}

The native chitosan with molecular weight (MW) of 1,077,919.278 $\mathrm{Da}$ and degree of deacetylation (DD) of $70.36 \%$ was synthesized from shrimp shell waste. Papain, sodium acetate, silver nitrate, acetic acid, sodium hydroxide and glucose $\left(\mathrm{C}_{6} \mathrm{H}_{12} \mathrm{O}_{6}\right.$ were purchased from Merck. MHA (Muller Hilton Agar), Bacteria of Escherichia coli (E.coli) and Stapbylococcus aureus(S.aureus) clinical isolate were purchased from Laboratory of Microbiology Medical Faculty Sebelas Maret University.

\section{Procedure}

Preparation of chitosan hydrolysate

The native chitosan solution was made with a concentration of $5.0 \mathrm{~g} / \mathrm{L}$ by dissolving chitosan in acetate buffer (acetitic acid sodium acetate - $\mathrm{pH}$ 4.5). The enzyme papain mixed with a weight ratio of papain / chitosan $=1: 4$, and incubated at room temperature for time variation of $1,5,25$ and $100 \mathrm{~h}$ to the hydrolysis reaction. This variation aims to produce the different weight of chitosan hydrolysates. Then, $1 \mathrm{M} \mathrm{NaOH}$ was added dropwise to the solution until $\mathrm{pH} 8$ and obtain 
a hydrolyzate of chitosan gel. Gel was washed with water until neutral, then filtered and dried. Hydrolyzate Chitosan dried crushed and screened 100 mesh. Samples were coded as $\mathrm{CH} 1, \mathrm{CH} 2, \mathrm{CH} 3$ and $\mathrm{CH} 4$.

\section{Preparation of silver nanoparticles}

A solution of chitosan hydrolysate $(1 \%$ $\mathrm{w} / \mathrm{v})$ in acetic acid solution $(1 \% \mathrm{v} / \mathrm{v})$ was firstly prepared. Due to the poor solubility of chitosan, the mixture was stirred to achieve complete dissolution, and then kept overnight at room temperature. The solution was filtered to remove any impurity perior to be used. Twenty five $\mathrm{mL}$ of chitosan hydrolysate $(\mathrm{CH} 4)$ $1 \%(\mathrm{~m} / \mathrm{V})$ was added salt of $\mathrm{AgNO}_{3}$ $(0.012 \mathrm{~g} / \mathrm{mL})$ at various volume: $0.2 \mathrm{~mL}, 0.6 \mathrm{~mL}$ and $1.0 \mathrm{~mL}$. The solution was stirred for $15 \mathrm{~min}$. Then add fresh glucose solution of $0.0501 \mathrm{~g} / \mathrm{mL}$ as reducing agents so that molar ratio between chitosan hydrolyzate $\mathrm{AgNO}_{3}$ and glucose reach 1:4. The solution was stirred for $15 \mathrm{~min}$ after addition of the reducing agent, was added $2 \mathrm{M} \mathrm{NaOH} 2.5 \mathrm{~mL}$ and stirred for $5 \mathrm{~min}$. Stirring was continued until $1 \mathrm{~h}$ to form silver nanoparticle stabilized by chitosan hydrolyzate (Ag/CH4). Because the sample is a liquid and gel, the gel was dissolved by adding $35 \mathrm{~mL}$ of $1 \%$ chitosan hydrolyzate. Sampel were coded as $\mathrm{Ag} / \mathrm{KH} 4 \mathrm{~A}, \mathrm{Ag} / \mathrm{KH} 4 \mathrm{~B}$, and $\mathrm{Ag} / \mathrm{KH} 4 \mathrm{C}$. The similar procedures were done for native chitosan (C) and other chitosan hydrolysate, i.e. CH1, $\mathrm{CH} 2, \mathrm{CH} 3, \mathrm{CH} 4$ with volume of $\mathrm{AgNO}_{3}$ of $1.0 \mathrm{~mL}$. The silver nanoparticle stabilized by various chitosan hydrolysate were coded as $\mathrm{Ag} / \mathrm{C}$, $\mathrm{Ag} / \mathrm{CH} 1, \mathrm{Ag} / \mathrm{CH} 2, \mathrm{Ag} / \mathrm{CH} 3$ and $\mathrm{Ag} / \mathrm{CH} 4$.

\section{Determination of chitosan hydrolysate molecular weight}

Molecular weight of chitosan was determined in triplicates by capillary viscometry at $30 \pm 0.05^{\circ} \mathrm{C}$ using an Oswalt viscometer. Filtered chitosan solutions $(0.05-0.2 \%)$ in $0.2 \mathrm{M} \quad \mathrm{CH}_{3} \mathrm{COOH} / 0.1 \mathrm{M} \quad \mathrm{CH}_{3} \mathrm{COONa}$ were equilibrated to $30^{\circ} \mathrm{C}$ prior to measurement of flow times. The intrinsic viscosity was determined by extrapolation of the graph of reduced viscosity against concentration. The molecular weight average $\mathrm{Mw}$ was calculated from the intrinsic viscosity [ $\eta]$ using the MarkHouwink equation $\left([\eta]=\mathrm{KMw}^{\mathrm{a}}\right)$ with $\mathrm{K}$ and a are $1.81 \times 10^{-3} \mathrm{~cm}^{3} \cdot \mathrm{g}^{-1}$ ) and 0.930 respectively. (Fouda, 2005)

\section{Characterization of silver nanoparticle}

Ultra violet-visible (UV-Vis) spectra have been proved to be sensitive to the formation of silver nanoparticles because they exhibit an intense absorption peak due to the surface plasmon resonance (SPR) phenomenon. It describes the collective excitation of conduction electrons in a metal. UV-Vis spectra were performed with a Shimadzu UV3150 UV-Vis spectrophotometer operating in the absorbance mode. UV-Vis absorption spectra of the samples were recorded in the wavelength range of 300 to $600 \mathrm{~nm}$ and all samples were diluted 10 times before analysis. While size and distribution of particles were characterized by Transmission electron microscopy JEM-2000EX at an accelerating voltage of $120 \mathrm{kV}$.

\section{Antibacterial activity test}

The antibacterial activity of the nanoparticles was evaluated against E. coli and $S$. aureus (clinical isolate) by the agar diffusion method with MHA (Muller Hilton Agar) as the medium. An aliquot of silver-nanoparticle dispersion $(20 \mu \mathrm{L})$ was added into well in a plate, and then incubated for $24 \mathrm{~h}$ at $37^{\circ} \mathrm{C}$. Antibacterial activity was measured as the diameter of the inhibitory zones in the plates.

\section{RESULTS AND DISCUSSION}

Chitosan hydrolysate with lower molecular weight than native chitosan was prepared from enzymatic hydrolysis with papain. Different molecular weight of chitosan hydrolysate can be produced by different time of hydrolysis duration as shown in figure 1 . At the $25 \mathrm{~h}$ duration of the process, chitosan hydrolysate is obtained with a significant decrease in molecular weight ie from 1.077.919,278 Da to $160.287,627 \mathrm{Da}$. When the time increased to $100 \mathrm{~h}$, the molecular weight does not change significantly.

Silver nanoparticles have been prepared by wet chemical method with Green synthesis approach. It was employed by using non toxic chemicals, environmentally benign solvents, renewable materials and energy efficiency. 


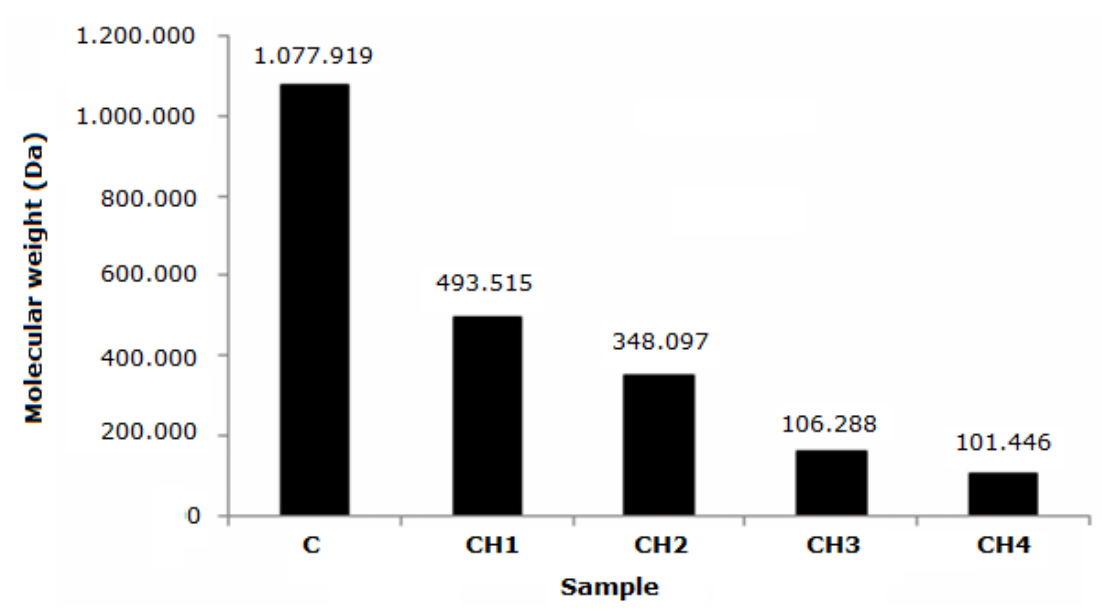

Figure 1. Molecular Weight of chitosan hydrolysate produced in various time of hydrolysis process

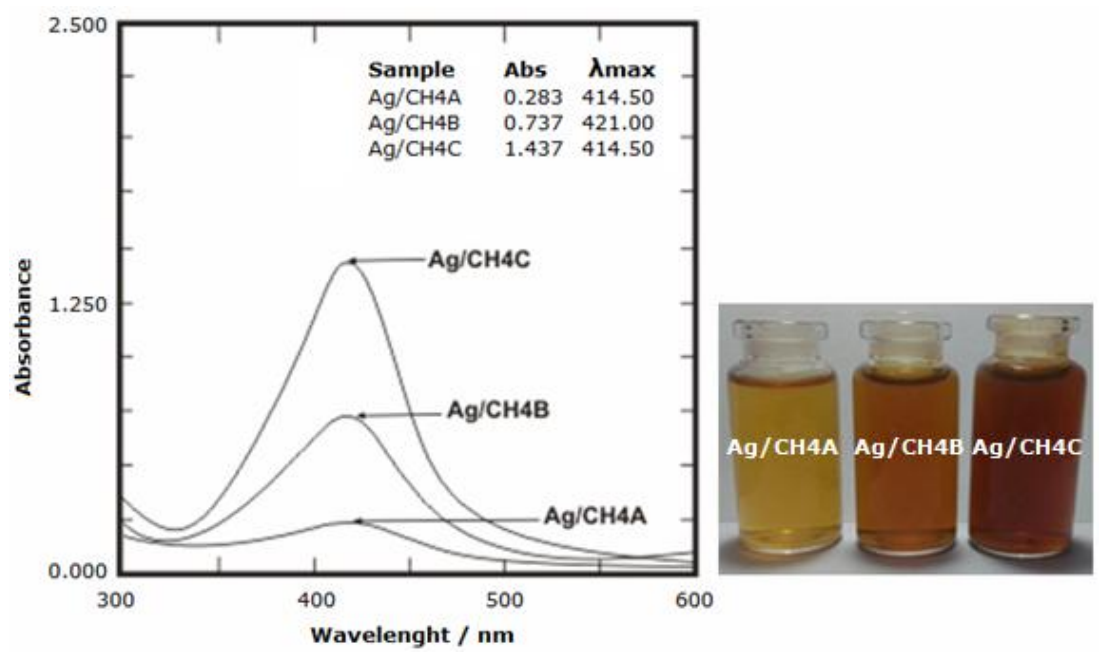

Figure 2. UV-Vis absorption spectra of silver nanoparticles and their colloidal color prepared at various concentrations of $\mathrm{AgNO}_{3}$

In the present work, we use water as solvent, glucose as reducing agent, chitosan hydrolysate (CH) as stabilizing agent and $\mathrm{NaOH}$ as an accelerator agent. Synthesis was conducted at ambient temperature and pressure. Because of glucose contain aldehyde moiety, so it can reduce silver ions to metallic silver and oxidize itself into glucolic acid. The possible step reactions during $\mathrm{Ag}$ Nanoparticles formation can be in the following:

$\mathrm{Ag}^{+}(\mathrm{aq})+(\mathbf{C H})(\mathrm{aq}) \rightarrow[\mathrm{Ag}(\mathbf{C H})]^{+}(\mathrm{aq})$ $2[\mathrm{Ag}(\mathbf{C H})]^{+}(\mathrm{aq})+2 \mathrm{OH}^{-}(\mathrm{aq})+\mathrm{C}_{5} \mathrm{H}_{11} \mathrm{O}_{5^{-}}$ $\mathrm{CHO}(\mathrm{aq}) \rightarrow 2 \mathrm{Ag}(\mathrm{s})+2(\mathbf{C H})(\mathrm{aq})+\mathrm{H}_{2} \mathrm{O}(\mathrm{l})+$ $\mathrm{C}_{5} \mathrm{H}_{11} \mathrm{O}_{5}-\mathrm{COOH}(\mathrm{aq})$
The color of the colloid resulted from different concentration of $\mathrm{AgNO}_{3}$ changed from yellow to brown and dark brown, as shown in figure 2 indicating the formation of $\mathrm{Ag}$ nanoparticles. The intense colors relate to the plasmon resonance absorption of silver nanoparticles. The surface of a metal is like a plasma, having free electrons in the conduction band and positively charged nuclei. Surface plasmon resonance (SPR) is a collective excitation of the electrons in the conduction band; near the surface of the nanoparticles (Guzman et al., 2009). 


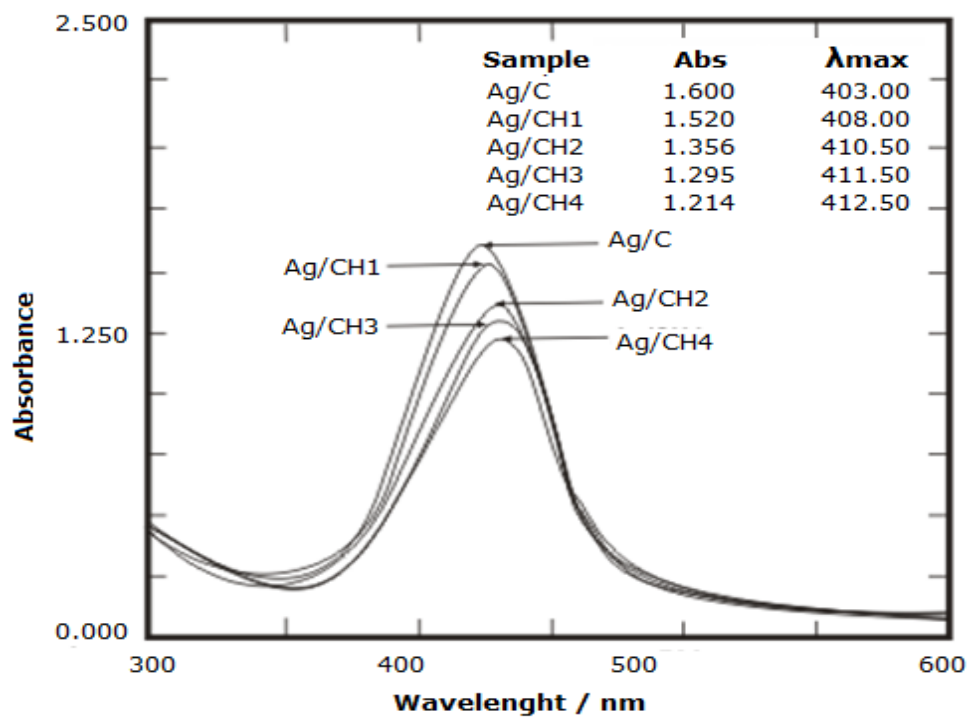

Figure 3. UV-Vis absorption spectra of silver nanoparticles prepared at various molecular weights of hydrolysate chitosan as a stabilizing agent
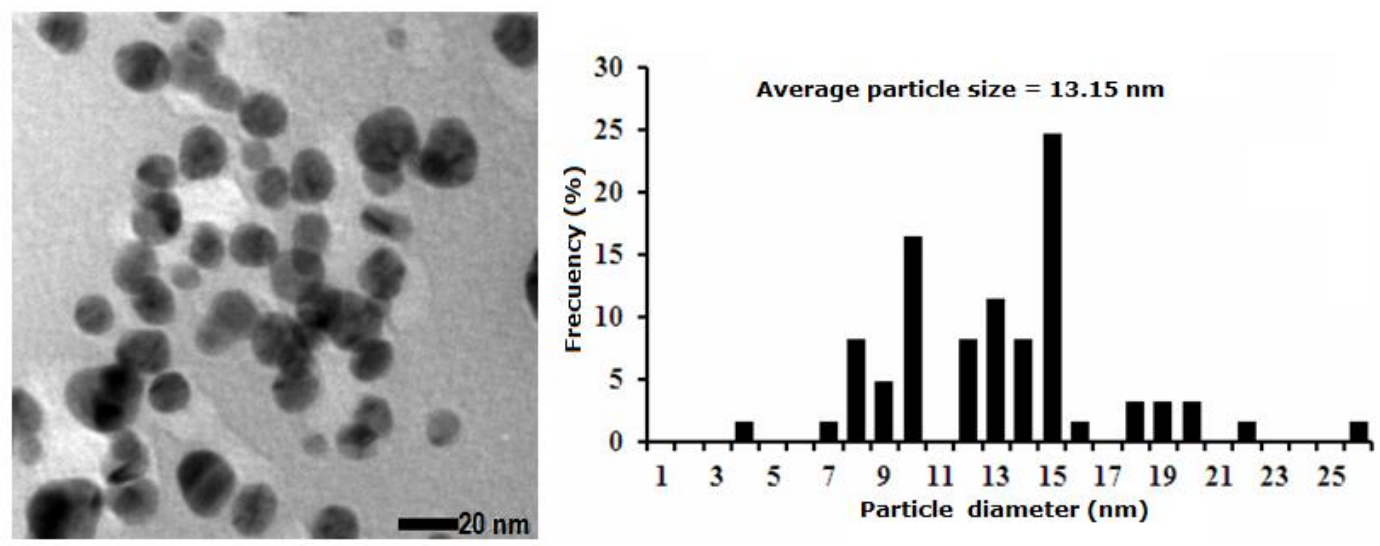

Figure 4. TEM image of silver nanoparticles and particle size distribution (sample Ag/CH4C)

Since electrons are limited to specific vibrations modes by the particle's size and shape metallic nanoparticles have characteristic of optical absorption spectrums in the UV-Vis region (Sileikaite et al., 2009).

The UV-Vis absorption spectra of $\mathrm{Ag}$ nanoparticles produced in various concentrations of silver nitrate are shown in figure 2 .The gradual increase in the $\mathrm{AgNO}_{3}$ concentration from $\mathrm{Ag} / \mathrm{CH} 4 \mathrm{~A}$ to $\mathrm{Ag} / \mathrm{CH} 4 \mathrm{~B}$ also increased absorbance indicating increase of silver nanoparticles concentration. The absorption peak due to SPR of silver nanoparticles was red-shifted (Ag/CH4A $\mathrm{Ag} / \mathrm{CH} 4 \mathrm{~B})$, indicating the increase of the size of the silver nanoparticles (Singh et al., 2007).

Meanwhile, the use of chitosan hydrolyzate as a stabilizer with a different molecular weight effect on the SPR as shown in figure 3. The lower the molecular weight of chitosan hydrolyzate decrease the amount of silver nanoparticles. The absorption peak due to SPR of silver nanoparticles was blue-shifted in the higher molecular weight of chitosan hydrolysate indicating the decrease of the size of the silver nanoparticles (Heath et al., 1989). 
(a)
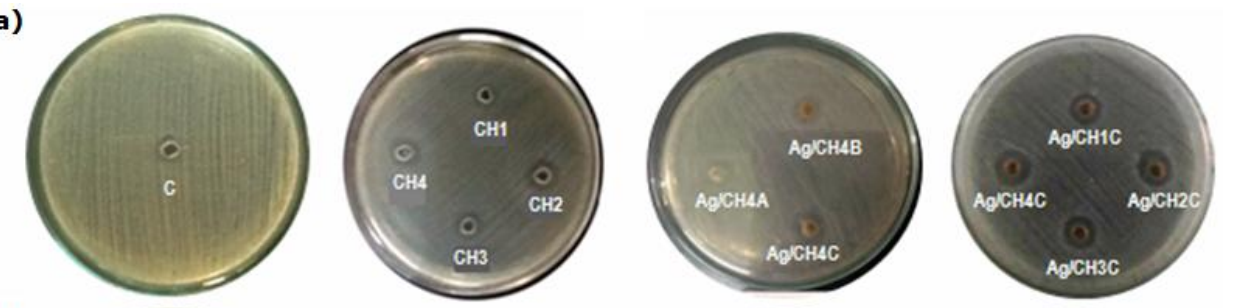

(b)
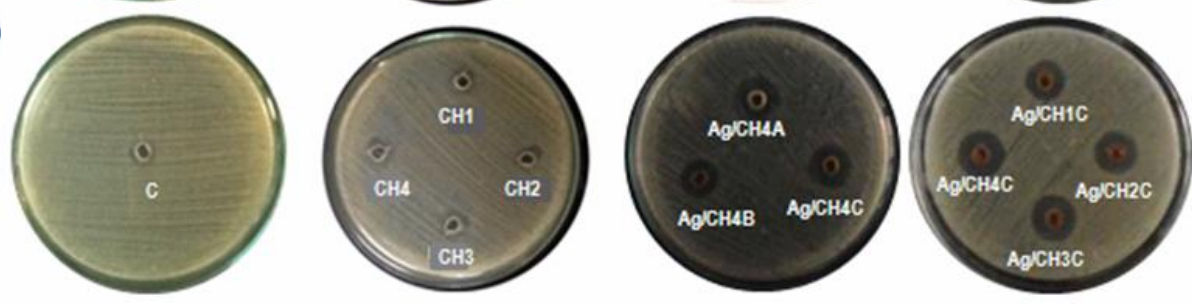

Figure 5. Inhibitory zone of chitosan (C), chitosan hydrolysate $(\mathrm{CH})$ and silver nanoparticles $(\mathrm{Ag} / \mathrm{CH})$ toward (a) S. Aureus and (b) E. coli

Table I. Inhibitory zone of chitosan $(\mathrm{C})$, chitosan hydrolysate $(\mathrm{CH})$ and silver nanoparticles $(\mathrm{Ag} / \mathrm{CH})$

\begin{tabular}{|c|c|c|}
\hline \multirow{2}{*}{ Sample } & \multicolumn{2}{|c|}{ Inhibitory Zona (mm) } \\
\hline & S. Aureus & E. Coli \\
\hline $\mathrm{C}$ & 9.3 & 9.0 \\
\hline CH1 & 10.0 & 10.0 \\
\hline $\mathrm{CH} 2$ & 10.6 & 10.6 \\
\hline $\mathrm{CH} 4$ & 11.3 & 11.3 \\
\hline $\mathrm{CH} 4$ & 12.6 & 12.6 \\
\hline $\mathrm{Ag} / \mathrm{CH} 1 \mathrm{C}$ & 14.2 & 10.0 \\
\hline $\mathrm{Ag} / \mathrm{CH} 2 \mathrm{C}$ & 15.3 & 10.2 \\
\hline $\mathrm{Ag} / \mathrm{CH} 3 \mathrm{C}$ & 16.2 & 11.3 \\
\hline $\mathrm{Ag} / \mathrm{CH} 4 \mathrm{~A}$ & 17.0 & 13.5 \\
\hline $\mathrm{Ag} / \mathrm{CH} 4 \mathrm{~B}$ & 17.1 & 14.0 \\
\hline $\mathrm{Ag} / \mathrm{CH} 4 \mathrm{C}$ & 17.5 & 15.5 \\
\hline
\end{tabular}

The single peak UV-Vis spectra around $400 \mathrm{~nm}$ in figure 2 and figure 3 indicated that silver nanoparticles are spherical in shape (Guzman et al., 2009). This is in line with image TEM as shown in figure 4 representated by sample $\mathrm{Ag} / \mathrm{KH} 3 \mathrm{C}$. The size of silver nanoparticles are in the range of $4-26 \mathrm{~nm}$ with average $13.15 \mathrm{~nm}$. This size suitable for use as an antibacterial material (Marambio-Jones and Hoek, 2010).

Antibacterial activity of chitosan, chitosan hydrolysate and silver nanoparticle against E. coli and $S$. aureus are idicated by inhibition zone $(\mathrm{mm})$ are shown in figure 5 and table I. Both chitosan and chitosan hydrolysate have antibacterial activity. Chitosan hydrolyzate with a lower molecular weight gives a higher antibacterial activity. This means that the diffusion process of chitosan hydrolisates with low molecular weight have better range than the native chitosan solution. There are three antibacterial posibility mechanisms (Goy et al, 2009) i.e, (1) the ionic surface interaction resulting in wall cell leakage; (2) the inhibition of the mRNA and protein synthesis via the penetration of chitosan into the nuclei of the microorganisms; and (3) the formation of an external barrier, chelating metals and provoking 
the suppression of essential nutrients to microbial growth. Meanwhile, incorporation of silver nanoparticle in chitosan hydrolysate increased the inhibition bacterial growth in dose-dependent way. The combination of chitosan hydrolysate with lower molecular weight and silver nanoparticle with higher concentration (Ag/CH4A to $\mathrm{Ag} / \mathrm{CH} 4 \mathrm{C})$ showed higher bacterial growth inhibition. In the same concentration of silver precursor with lower molecular weight of chitosan hydrolysate ( $\mathrm{Ag} / \mathrm{CH} 1 \mathrm{C}$ to $\mathrm{Ag} / \mathrm{CH} 3 \mathrm{C})$ increase the inhibition zone even though the silver nanoparticles slightly decrease as shown in figure 3. According to table 1, all samples silver nanoparticles with chitosan hydrolysate showed high antibacterial toward E. coli and S. aureus. Although the exact mechanism for the growth inhibition by silver nanoparticles has not yet been elucidated, but the prevailing paradigm suggests various combinations of: (1) silver ion release followed by cellular uptake and a cascade of intracellular reactions, (2) extracellular and intracellular generations of reactive oxygen species (ROS), and (3) direct interactions between nano-scaled silver and cell membranes (Marambio-jones and Hoek, 2010).

\section{CONCLUSION}

We have demonstrated a green synthesis of silver nanoparticles with chitosan hydrolysate as stabilizing agent and glucose as reducing agent. The formation of silver nanoparticles was shown by the appearance of surface plasmon resonance (SPR) at 403$421 \mathrm{~nm}$ from the corresponding UV-Vis spectra. To produce silver nanoparticles with greater concentration, higher molecular weight chitosan hydrolysate and higher concentration of silver precursor was required. Silver nanoparticles were spherical in shape as identified by TEM images with size in range of 4-26nm. The silver nanoparticles with chitosan hydrolysate as stabilizing agent have shown high antibacterial activity against E. coli and S. aureus.

\section{ACKNOWLEDGEMENTS}

The author would like to thank to DP2M Dikti who gave financial support through PUPT Grant 2014 of Universitas Sebelas Maret.

\section{REFERENCES}

Chen JI., Han CM., Lin XW., Tang ZJ., Su SJ. 2006. Effect of silver nanoparticle dressing on second degree burn wound. Chinese journal of surgery. 44 (1):50-52.

Chudasama B., Vala AK., Andhariya N., Mehta RV. and Upadhyay RV. 2010. Highly bacterial resistant silver nanoparticles: synthesis and antibacterial activities. J. Nanopart. Res. 12:1677-1685.

Cai J., Kimura S., Wada M., Kuga S. 2009. Nanoporous cellulose as metal nanoparticles support. Biomacromolecules. 10:87-94.

Darroudi M., Ahmad MB., Abdullah AH., Ibrahim NA., Shameli K. 2010. Effect of Accelerator in Green Synthesis of Silver Nanoparticles. Int. J. Mol. Sci. 11:3898-3905.

Faraha AA., Alvarez-Puebla RA., Fenniri H., 2008. Chemically stable silver nanoparticle-crosslinked polymer microspheres. J. Colloid Interf. Sci., 319:572-576.

Fouda MMG., 2005. Use of Natural Polysacharides in Medical Textile Application. Disertasi. Fedbereich Chimie Universitat Duisburg-Essen. Germany.

García-Barrasa J., López-de-Luzuriaga JM., Monge M. 2011, Silver nanoparticles: synthesis through chemical methods in solution and biomedical applications. Cent. Eur. J. Chem. 9(1):7-19.

Goy RC., Britto DD., Assis OBG. 2009. A Review of the Antimicrobial Activity of Chitosan. Polímeros: Ciência e Tecnologia, 19(3):1-7.

Guzmán MG., Dille J., Godet S. 2009. Synthesis of silver nanoparticles by chemical reduction method and their antibacterial activity. I. J. Chem. Biological Engineering. 2(3):104-111.

Heath JR., 1989. Size dependent surface plasmon resonances in bare silver particles. Phys. Rev. B. 40:9982-9985.

Honary S., Ghajar K., Khazaeli P., Shalchian P. 2011. Preparation, Characterization and Antibacterial Properties of SilverChitosan Nanocomposites Using Different Molecular Weight Grades of Chitosan. Trop. J.Pharm. Res. 10(1):69-74. 
Huang H., Yuan Q., Yang X. 2004. Preparation and characterization of metal-chitosan nanocomposites. Colloid Surface B. 39:3137.

Kim KM., Son JH., Kim SK., Weller CL., Hanna MA. 2006. Properties of Chitosan Films as a Function of $\mathrm{pH}$ and Solvent Type. J. Food Sci. E: Food Engineering and Physical Properties, 71(3):119-124.

Lin H., Wang H., Xue C., Ye M., 2002. Preparation of chitosan oligomers by immobilized papain. Enzyme and Microbial Technology. 31:588-592.

Luo C., Zhang Y., Zeng X., Zeng Y., Wang Y. 2005. The role of poly(ethylene glycol) in the formation of silver nanoparticles. $J$. Colloid Interf. Sci. 288:444-448.

Marambio-Jones C., Hoek EV. 2010. A review of the antibacterial effects of silver nanomaterials and potential implications for human health and the environment. J. Nanopart Res. 12:1531-1551.

Pranoto Y., Rakshit SK., Salokhe VM. 2005. Enhancing antimicrobial activity of chitosan films by incorporating garlic oil. LWT-Food Sci Technol. 38 :859-65.

Qin, C., Du, Y., Xiao, L., Li Z. and Gao, X. 2002. Enzymic preparation of watersoluble chitosan and their antitumor activity. Int. J. Biol. Macromol. 31:111-117.

Raveendran P., Fu J., Wallen, S.L. 2003. Completely "green" synthesis and stabilization of metal nanoparticles. $J$. Am. Chem. Soc. 125:13940-13941.

Roe D., Karandikar B., Bonn-Savage N., Gibbins B., Roullet JB. 2008.
Antimicrobial surface functionalization of plastic catheters by silver nanoparticles. J. Antimicrob. Chemother. 61 (4): 869-876.

Singh N., Sinha I., Mandal RK. 2009. Role of $\mathrm{pH}$ in the green synthesis of silver nanoparticles. Materials Letters. 63:425427

Shameli K., Ahmad MB., Yunus WMZW., Ibrahim NA., Gharayebi Y., Sedaghat S., 2010, Synthesis of silver/ montmorillonite nanocomposite using $\gamma$ irradiation, Int. J. Nanomed., 5:1067-1077

Šileikaitè A., Puišo J., Prosyčevas I., Tamulevičius S. 2009. Investigation Of Silver Nanoparticles Formation Kinetic During Reduction Of Silver Nitrate With Sodium Citrate. Mater. Sci.(Medřiagotyra). 15(1):21-27

Vorobyova SA., Lesnikovich AI., Sobal NS. 1999. Preparation of Silver Nanoparticles by Interphase Reduction. Colloids Surf. A. 152:375-379

Xie H. 2011. Preparation of Low Molecular Weight Chitosan by Complex Enzymes Hydrolysis. Int. J.Chem.3(2):180-186

Zheng M., Gu M., Jin Y., Jin G. 2001. Optical Properties of Silver-Dispersed PVP Thin Film. Mater. Res. Bull. 36:853-859.

Zhou Y., Yu SH., Wang CY., Li XG., Zhu YR., Chen ZY. 1999, A novel ultraviolet irradiation photo-reduction technique for preparation of single crystal $\mathrm{Ag}$ nanorods and Ag dendrites. Adv. Mater. 11:850-852. 